\title{
Effect of potassium to bivalent cations ratio in irrigation water on some physical and hydraulic properties of sandy loam soil
}

\author{
Maasoume Zaker ${ }^{l}$ and Hojat Emami ${ }^{* 2}$ \\ ${ }^{1}$ Former M.Sc. Student of Soil Science Department, Faculty of Agriculture, \\ Ferdowsi University of Mashhad- Iran \\ ${ }^{2}$ Associate Professor of Soil Science Department, Faculty of Agriculture, Ferdowsi University of Mashhad- Iran
}

\begin{abstract}
Cation ratio of soil structural stability (CROSS) was used to evaluate the effects of potassium to calcium and magnesium ratio in irrigation water on soil properties of a sandy loam. For this purpose, a research was performed as a completely randomized design in undisturbed soil columns. Experimental factors were salinity (4 and $8 \mathrm{dS} \mathrm{m}^{-1}$ ) and CROSS of irrigation water (10, 15, 20 and 25). After 16 weeks, water dispersible clay (DC), saturated hydraulic conductivity (Ks), slope of retention curve at inflection point ( $S$ index), moisture content at field capacity $(F C)$, permanent wilting point $(P W P)$ and plant available water content $(P A W C)$ were measured. The results showed that potassium ions in irrigation water significantly decreased $D C, K s, P A W C$, and $S$ index. The effect of potassium on soil physical properties depended on the total concentration of solutes. According to the results, it is suggested that the effects of potassium for assessing the soil structure should be considered.
\end{abstract}

Keywords: Cation ratio of soil structural stability, soil degradation, potassium, clay dispersion, hydraulic conductivity

\section{Introduction}

Soil salinity is one of the most damaging environmental factors, particularly in arid and semi-arid regions of the world (Ashraf et al., 2017). Marginal waters for irrigation such as industrial wastewater, saline groundwater and agricultural drainage water are used in this region too. Estimates indicate that 34 million hectares, including 4.1 million hectares of irrigated lands in Iran are suffering from different kinds of salinization (Moghbel et al., 2017). Saline irrigation water may decline soil performance through soil sodicity induced by irrigation that causes soil structural problems and specific ion effect on crops. The ratio of sodium to the sum of calcium and magnesium (SAR) in irrigation water or soil extract is the most common criterion which is considered as sodicity and structural stability of soils (Rengasamy and Marchuk, 2011). The concentration of potassium is not considered in this ratio and the impact of calcium and magnesium ions in this term to flocculate soil particles and to create aggregate is assumed to be similar. Potassium is a monovalent cation and can create clay dispersion and swelling. It has been shown that potassium and magnesium ions on the exchangeable sites of soil may lead to clay dispersion when the soil exchangeable sodium is minimal (Marchuk and Rengasamy, 2012). Also, Keren (1991) found that exchangeable magnesium under given condition can damage soils structure. Contradictory effects of potassium on soil structure have been reported in literature. For example, it has been reported that potassium has less or even equal effect on soil structure compared to sodium (Chen et al., 1993; Farahani et al., 2018a, 2018b). Quirk and Schofield (1955) found that potassium as well as sodium is destructive, but Levy and Torrento (1995) reported that potassium is not destructive and does not reduce the stability of macro-aggregate.

Keren and Singer (1988) and Kosmas and Moustakas (1990) reported that replacement of an electrolyte solution containing high ion concentration with deionized water, led to clay dispersion and sharply decreased $K_{s}$. High concentrations of hydrated sodium and potassium cause clay dispersion, resulting in reduced infiltration rate, earlier/increased runoff, and increased sediment concentrations (Auerswald et al., 1996). Moreover, soils containing sodium and magnesium represent higher DC and lower Ks than those containing sodium and calcium (Emerson and Smith, 1970). It has been found that magnesium has a great effect on clay dispersion through reducing the infiltration, surface crusting and increasing the soil erosion (Dontsova et al, 2002). Rengasamy and Marchuk (2011) used "Cation Ratio of Soil Structural Stability (CROSS)," analogous to SAR but CROSS selectively incorporates the individual dispersive effects of $\mathrm{Na}^{+}$and $\mathrm{K}^{+}$, and the individual flocculating effects of $\mathrm{Mg}^{+2}$

\footnotetext{
*Email: hemami@um.ac.ir
} 
and $\mathrm{Ca}^{+2}$ (Eq. 1), while in SAR only dispersive effects of $\mathrm{Na}^{+}$ to flocculating power of $\mathrm{Ca}^{2+}$ and $\mathrm{Mg}^{2+}$ was regarded. In addition, in CROSS the dispersive power of $\mathrm{Na}^{+}$is more than $\mathrm{K}^{+}$and flocculating power of $\mathrm{Ca}^{2+}$ more than $\mathrm{Mg}^{2+}$. Arienzo et al. (2009) found that an increase in exchangeable potassium and sodium had a negative impact on Ks and infiltration rate. Furthermore, the Ks decreased following long-term use of sewage containing low to high amounts of potassium. Mandal et al. (2008) found that replacing the saline-sodic irrigation water by waste water, with significantly lower salinity and sodicity levels, may prove beneficial in improving soil structural stability and could also mitigate problems associated with high levels of runoff and soil erosion, particularly in regions with moderate rainfall intensities. Bagarello et al. (2006) diluted the sodic soil water ( $\mathrm{SAR}=0,10,20$, and 30 ) by deionized water and found that it decreased the saturated and/or field saturated hydraulic conductivity in a salt-affected sandy loam and clay soils in western Sicily.

Ahmad et al. (2006) reported that the destructive effects of potassium ions are as same as sodium ions in a tropical red soil, consisting predominantly of kaolin and iron oxide, effects similar to $\mathrm{Na}$ on percentage stable aggregates and hydraulic conductivity. They suggest that heavy potash fertilization may lead to structural deterioration of these soils. Smiles (2006) noted that expansion and dispersion of clays due to small amount of potassium in the soil are ignored, while it's important in salt-affected soils. Rengasamy and Marchuk (2011) demonstrated that the use of waters with high potassium can decrease the water infiltration into soil. Farahani et al. (2018a, 2018b, 2019) found that adding potassium into soils caused clay dispersion, and negatively affected some soil physical and mechanical properties. It was found that clay dispersion significantly increased with increasing potassium concentration only when the concentration was above a critical potassium concentration.

Most investigations on clay dispersion have concentrated on the effect of highly exchangeable sodium on soil structure and stability (Rengasamy, 2002). Only few studies have shown that potassium and sodium in the exchange complexes can also affect the soil structure (Rengasamy, 2006; Smiles, 2006; Arienzo et al., 2009; Emami et al., 2014). The destructive effects of $\mathrm{Na}^{+}$

Table 1: Concentration of cations in irrigation water in different treatments

\begin{tabular}{|c|c|c|c|c|}
\hline CROSS & $E C\left(d S m^{-1}\right)$ & $\mathrm{K}\left(\mathrm{meq} \mathrm{\mathbf {l } ^ { - 1 } )}\right.$ & Ca $\left(\right.$ meq l$\left.^{l^{-1}}\right)$ & $\operatorname{Mg}\left(\right.$ meq I $\left.^{-1}\right)$ \\
\hline 10 & 4 & 33.16 & 3.42 & 5.70 \\
\hline 15 & 4 & 36.32 & 3.06 & 1.84 \\
\hline 20 & 4 & 37.00 & 1.00 & 2.00 \\
\hline 25 & 4 & 38.00 & 0.62 & 1.38 \\
\hline 10 & 8 & 54.10 & 8.50 & 17.40 \\
\hline 15 & 8 & 64.00 & 5.50 & 10.50 \\
\hline 20 & 8 & 69.25 & 3.35 & 7.40 \\
\hline 25 & 8 & 72.80 & 2.50 & 4.70 \\
\hline
\end{tabular}

Table 2: Some initial properties of soil

\begin{tabular}{lcl}
\hline Soil property & & Value \\
Sand & & 69 \\
Silt & $(\%)$ & 20 \\
Clay & - & 11 \\
\hline Texture & - & Sandy Loam \\
Clay Mineralogy & - & Mica \\
pH & $\%$ & 8.02 \\
\hline Lime & ${\mathrm{cmole}(+) \mathrm{kg}^{-1}}^{-1}$ & 16.41 \\
Organic matter & $\mathrm{dS} \mathrm{m}$ & 0.32 \\
\hline Cation exchange capacity & & 1.04 \\
Electrical conductivity & & 4.05 \\
\hline $\mathrm{Na}^{+}$ & $\mathrm{meq} \mathrm{I}^{-1}$ & 0.5 \\
$\mathrm{~K}^{+}$ & & 3.07 \\
$\mathrm{Ca}^{+2}$ & & 2.77 \\
$\mathrm{Mg}^{+2}$ & & \\
\hline
\end{tabular}

and a tropical black soil consisting predominantly of montmorillonite. Their results showed that $\mathrm{K}$ ions have concentration on DC and Ks have been demonstrated in literature (e.g., McNeal and Coleman, 1966; Emerson and 
Smith, 1970; Rengasamy and Marchuk, 2011), and soils with different amounts of sodium, potassium, calcium and magnesium have been studied. However, the effects of potassium and sodium have been less investigated (Chen $e t$ al., 1993; Marchuk and Rengasamy, 2012; Emami et al., 2014). On the other hand, the individual effect of $\mathrm{K}^{+}$on soil physical and structural properties, especially $\mathrm{S}$ index, moisture content at FC, PWP, and PAWC was not studied. Therefore, this study was performed to investigate the effect of potassium to calcium and magnesium ratio in different salinity values of irrigation water on some soil physical and structural properties. For this purpose, in the present study, the used salts for irrigation were sodium free and just potassium, calcium and magnesium salts were applied in irrigation water through equal CROSS index.

\section{Materials and Methods}

A sandy loam soil column weas taken from an agricultural field in Neyshabour town which is located in Khorasan Razavi Province (Iran), with the longitude of $58^{\circ}$ $32^{\prime} 59^{\prime \prime}$ and latitude of $36^{\circ} 14^{\prime} 10^{\prime \prime}$. To evaluate the effect of salinity and CROSS of irrigation water, a completely randomized design with three replications in factorial arrangement was performed. Treatments included two salinity levels (4 and $8 \mathrm{dS} \mathrm{m}^{-1}$ ) and four levels of CROSS $(10,15,20$ and 25), while the characteristics and composition of treatments are shown in Table 1. The calcium, magnesium and potassium chlorides were used to prepare the solutions. So that at each salinity level, the CROSS of solutions was 10, 15, 20 and 25. CROSS was determined as (Rengasamy and Marchuk, 2011):

$$
\text { CROSS }=\frac{\mathrm{Na}+0.56 \mathrm{~K}}{\sqrt{\frac{\mathrm{Ca}+0.6 \mathrm{Mg}}{2}}}
$$

where the concentrations of cations are in $\mathrm{mmol}_{\mathrm{c}} \mathrm{L}^{-1}$. The coefficient of $\mathrm{K}(0.56)$ was based on the relative dispersive power of $\mathrm{Na}$ and $\mathrm{K}$, and the coefficient of $\mathrm{Mg}(0.6)$ was based on the relative flocculating power of $\mathrm{Ca}$ and $\mathrm{Mg}$ (Rengasamy and Marchuk, 2011). The properties of studied soil are shown in Table 2. EC, pH and concentration of cations were measured in extract of saturated paste. In addition, mica is a dominant clay mineral in studied soil.

The undisturbed soil columns were prepared. For this purpose, polyethylene cylinders (height: $30 \mathrm{~cm}$, and diameter: $10 \mathrm{~cm}$ ) which had a sharp cutting edge at their base to facilitate their penetration into the soil were pushed into the soil without rotation, displacing the soil as they penetrate. More details about collecting the undisturbed soil samples have been explained by Lewis and Sjöstrom (2010). These columns were irrigated with treatment solution for 16 weeks. The interval of irrigation was 7 days and 0.5 liters of solutions were added to each soil column at irrigation time. This volume was more than the moisture at field capacity (FC), therefore the solutions were homogenously distributed in soil column. After 16 weeks of irrigation, undisturbed soil samples were taken from a depth of $10-15 \mathrm{~cm}$ to measure moisture curves with pressure plate apparatus at pressure heads of 10, 30, 50, 100, 300, 500, 1000 and 1500 $\mathrm{kPa}$. In addition, saturated water content was also measured. The measured soil moisture data was fitted to the Van Genuchten equation (1980) using the RETC software as below:

$$
\theta=\theta_{r}+\left(\theta_{s}-\theta_{r}\right)\left[1+(\alpha h)^{n}\right]^{\frac{1}{n-1}}
$$

Based on parameters of SWRC, slope of retention curve at inflection point ( $S$ index) was obtained using following equation (Dexter, 2004):

$$
S=-n\left(\theta_{s}-\theta_{r}\right)\left[\frac{2 n-1}{n-1}\right]^{\left(\frac{1}{n}-2\right)}
$$

In these equations (1 and 2), $\Theta\left(\mathrm{g} \mathrm{g}^{-1}\right)$ is the moisture content at a given matric suction $\mathrm{h}(\mathrm{cm})$, and $\Theta_{\mathrm{s}}$ and $\Theta_{\mathrm{r}}$ are the saturated and residual water contents $\left(\mathrm{g} \mathrm{g}^{-1}\right)$, respectively, $\alpha$ is a scaling factor $\left(\mathrm{cm}^{-1}\right)$ and $n$ is a shape parameter of the soil water retention curve (SWRC).

The amount of plant available water content (PAWC) was calculated by subtracting $\mathrm{FC}$ from the permanent wilting point (PWP), where FC and PWP are the water contents at pressure heads of 30 and $1500 \mathrm{KPa}$, respectively. Saturated hydraulic conductivity (Ks) was measured by constant head method in undisturbed soil column in laboratory (Klute and Direksen, 1986). The urban tap water was used for this purpose.

To measure soil chemical properties, disturbed samples from the columns were collected, dried and sieved from 2 $\mathrm{mm}$ sieve. The method of Marchuk et al. (2013) was used to measure DC in water.

Some other chemical properties of soil, such as $\mathrm{pH}$ of saturated paste, and EC (electrical conductivity) saturated soil paste extract were measured by $\mathrm{pH}$ meter (model JENWAY 4310), and EC meter (model METROHM632). Calcium and magnesium concentrations were determined using soil extract titration with $0.01 \%$ normal EDTA and potassium was measured by flame photometer. Comparison of means was done by Duncan test at $p<0.05$. 


\section{Results and Discussion}

\section{The effect of salinity and CROSS of irrigation water on dispersible clay}

The results of analysis of variance (ANOVA) showed that the effect of salinity on DC, PWP, PAWC, and S index was significant $(p<0.01)$, but it had no significant effect on Ks and FC. The effects of CROSS on DC $(p<0.001)$, PWP, PAWC, S index $(p<0.01), \mathrm{Ks}$ and FC $(p<0.05)$ were significant (Table 3 ). The interaction effects of salinity and CROSS on DC $(p<0.001), \mathrm{S}$ index, PWP $(p<0.01)$, Ks, and PAWC $(p<0.05)$ were significant, too, but it had no significant effect on FC (Table 3). According to the results of ANOVA (Table 3) and comparison of means (Table 4), it can be said that CROSS or potassium ions in irrigation water had the greatest effect on DC and the lowest one on FC. irrigated with wastewater containing sodium and potassium and reported that the unsuitable changes of soil structure in higher salinity got reduced.

When CROSS contents of irrigation water increased, DC values showed an increasing trend (Table 4). There was no significant difference between low amounts of CROSS (10 and 15) in the DC in the soil. Higher the CROSS value, higher the DC, and the differences between high values of CROSS and low ones were significant $(p<0.05)$. In addition, the correlation coefficient between the CROSS of irrigation water and the amount of DC was positive and equal to 0.9 ( $p<0.01)$. There is little literature about the CROSS index. Marchuk and Rengasamy (2012) found that the CROSS values and the amount of clay dispersion highly positive correlated and the clay dispersion increased by increasing the amount of CROSS. Despite a positive

Table 3: The results of analysis of variance for studied soil properties

\begin{tabular}{|c|c|c|c|c|c|c|c|}
\hline \multirow[t]{2}{*}{ Source of variation } & \multirow{2}{*}{$\begin{array}{l}\text { Degree of } \\
\text { freedom }\end{array}$} & \multicolumn{6}{|c|}{ Mean of square } \\
\hline & & DC & KS & $\mathrm{S}$ index & FC & PWP & PAWC \\
\hline Salinity (A) & 1 & $31.00^{* *}$ & $0.001^{\mathrm{ns}}$ & $0.001^{* *}$ & $0.001^{\mathrm{ns}}$ & $0.001^{* *}$ & $0.001^{* *}$ \\
\hline CROSS & 3 & $88.33^{* * * *}$ & $0.001 *$ & $0.001^{*}$ & $0.007^{*}$ & $0.003^{* *}$ & $0.006^{* *}$ \\
\hline Salinity $\times$ CROSS & 3 & $78.72^{* * * *}$ & $0.001 *$ & $0.001 * *$ & $0.01^{\mathrm{ns}}$ & $0.004^{* *}$ & $0.001^{*}$ \\
\hline Error & 16 & 23.14 & 0.001 & 0.001 & 0.009 & 0.003 & 0.001 \\
\hline Total & 23 & & & & & & \\
\hline
\end{tabular}

$* * * *, * * *, * *$, and $*$ are significant at $p<0.0001,0.001,0.01,0.05$, respectively, and ns is not significant.

Table 4: Effect of salinity and CROSS of irrigation water on physical and hydraulic properties of soil

\begin{tabular}{lllllll}
\hline & DC $(\%)$ & Ks $\left(\mathbf{c m ~ d a y}^{-1}\right)$ & $\mathbf{F C ~}\left(\mathbf{c m}^{\mathbf{3}} \mathbf{c m}^{-3}\right)$ & $\mathbf{P W P}\left(\mathbf{c m}^{\mathbf{3}} \mathbf{c m}^{-3}\right)$ & $\mathbf{P A W C}\left(\mathbf{c m}^{\mathbf{3}} \mathbf{c m}^{-\mathbf{3}}\right)$ & $\mathbf{S}$ index \\
\hline $\mathrm{EC}=4$ & $5.790 \mathrm{a}$ & $3.70 \mathrm{a}$ & $0.22 \mathrm{a}$ & $0.17 \mathrm{~b}$ & $0.07 \mathrm{a}$ & $0.045 \mathrm{a}$ \\
$\mathrm{EC}=8$ & $3.52 \mathrm{~b}$ & $3.85 \mathrm{a}$ & $0.23 \mathrm{a}$ & $0.16 \mathrm{a}$ & $0.06 \mathrm{~b}$ & $0.034 \mathrm{~b}$ \\
\hline $\mathrm{CROSS}=10$ & $3.18 \mathrm{c}$ & $5.81 \mathrm{a}$ & $0.21 \mathrm{~b}$ & $0.15 \mathrm{c}$ & $0.06 \mathrm{~b}$ & $0.045 \mathrm{a}$ \\
$\mathrm{CROSS}=15$ & $2.50 \mathrm{c}$ & $3.71 \mathrm{~b}$ & $0.26 \mathrm{a}$ & $0.16 \mathrm{~b}$ & $0.10 \mathrm{a}$ & $0.038 \mathrm{~b}$ \\
$\mathrm{CROSS}=20$ & $5.68 \mathrm{~b}$ & $2.64 \mathrm{~b}$ & $0.23 \mathrm{ab}$ & $0.17 \mathrm{a}$ & $0.06 \mathrm{~b}$ & $0.035 \mathrm{c}$ \\
$\mathrm{CROSS}=25$ & $7.27 \mathrm{a}$ & $2.93 \mathrm{~b}$ & $0.21 \mathrm{~b}$ & $0.17 \mathrm{a}$ & $0.04 \mathrm{c}$ & $0.039 \mathrm{~b}$ \\
\hline
\end{tabular}

Same letters in each column are not significant $(p<0.05)$.

The effect of salinity (electrolyte concentration) of irrigation water on DC showed that the amount of DC in salinity of $4 \mathrm{dS} \mathrm{m}^{-1}$ was significantly $(p<0.05)$ more than that of $8 \mathrm{dS} \mathrm{m} \mathrm{m}^{-1}$ (Table 4). This result showed that low concentrations of bivalent cations in salinity of $4 \mathrm{dS} \mathrm{m} \mathrm{m}^{-1}$ couldn't prevent the destructive effects of potassium cation on clay dispersion in soil. Quirk and Schofield (1955) and Laurenson (2010) found that the destructive effects of high amounts of sodium and potassium on soil structure decreased by increasing the salinity. Moosavi and Sepakhah (2012) reported that saline waters with electrical conductivity less than $\sim 10 \mathrm{dS} \mathrm{m}^{-1}$ for irrigation can improve the soil hydraulic properties. Mandal et al. (2008) found that replacing the saline-sodic irrigation water by waste water may improve soil structural stability due to high organic matter. Laurenson (2010) also studied the structure of soils which have been relationship between the DC and CROSS in different soils, but slope of this relationship was significantly different in different soils (Farahani et al., 2018a, and 2018b). According to our results, it can be concluded that despite there was no sodium in irrigation water, CROSS or potassium can create clay dispersion.

The interaction effect of salinity and CROSS in irrigation water on DC (Figure 1) showed that in salinity of $8 \mathrm{dS} \mathrm{m} \mathrm{m}^{-1}$, there was no significant difference between different levels of CROSS ( $p<0.05)$. While for salinity of 4 $\mathrm{dS} \mathrm{m} \mathrm{m}^{-1}$ when the CROSS values of irrigation water increased the amount of DC significantly increased, so that the highest amount of DC was found at $\mathrm{EC}=4 \mathrm{dS} \mathrm{m}^{-1}$ and $\mathrm{CROSS}=25$, where this treatment included the lowest content of salinity and the highest value of CROSS in irrigation water, and following that treatment, $\mathrm{EC}=4 \mathrm{dS} \mathrm{m}^{-1}$ and $\mathrm{CROSS}=20 \mathrm{had}$ 
the high amount of DC, too. The least amount of DC was related to salinity of $4 \mathrm{dS} \mathrm{m}^{-1}$ and $\mathrm{CROSS}=15$ that had no significant difference with salinity of $4 \mathrm{dS} \mathrm{m}^{-1}$ and $\mathrm{CROSS}=10$ (Figure 1). These results indicated that the high concentrations of cations (higher EC values) in salinity of 8 $\mathrm{dS} \mathrm{m}{ }^{-1}$ prevents the destructive effects of potassium ions and clay dispersion under these conditions was not changed significantly. While in salinity of $4 \mathrm{dS} \mathrm{m} \mathrm{m}^{-1}$ (lower EC values), an increase in the CROSS values, concentration of bivalent cations $\left(\mathrm{Ca}^{2+}\right.$ and $\left.\mathrm{Mg}^{2+}\right)$ could not compensate the destructive effects of potassium. According to the results of this research, it can be said that the effects of mono-valent cations especially potassium on soil structural properties such as clay dispersion is strongly dependent on the concentration of electrolytes, and ratio of potassium to bivalent cations or CROSS may represent the destructive effects in dilute electrolytes.

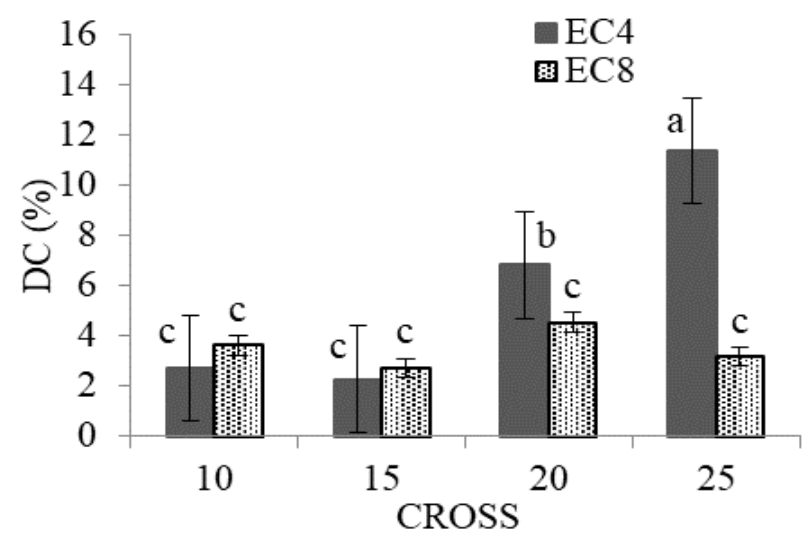

Figure 1: Interaction effect of salinity and CROSS of irrigation water on dispersible clay (similar letters indicate no significant differences among all bars at $p<0.05$ ).

\section{The effect of salinity and CROSS of irrigation water on saturated hydraulic conductivity}

When the salinity of irrigation water increased from 4 to $8 \mathrm{dS} \mathrm{m}^{-1}$ (Table 4 ), the $\mathrm{Ks}$ slightly increased too, but it was not significant $(p<0.05)$. It seems that due to simultaneous increase of $\mathrm{K}^{+}$and $\mathrm{Ca}^{2+}$ and $\mathrm{Mg}^{2+}$, salinity had no significant impact on Ks. Literature review show that when exchangeable sodium percent (ESP) and exchangeable potassium percent (EPP) is high, high value of soil salinity will flocculate clay particles and decrease the adverse effect on Ks (Shainberg et al., 1981; Levy and Torrento, 1995; Quirk, 2001). Increasing the CROSS values in irrigation water from 10 to 15 decreased $\mathrm{Ks}$ significantly. By increasing the CROSS values from 15 to 25 no significant differences were found between $\mathrm{Ks}$ value, even it slightly decreased when CROSS increased from 20 to 25 . It seems that, high concentration of potassium due to clay dispersion and aggregate stability decreased the diameter of pores and thus Ks, but a higher value of CROSS as a result of simultaneous increase of $\mathrm{K}^{+}, \mathrm{Ca}^{2+}$ and $\mathrm{Mg}^{2+}$ value cannot further reduce Ks. Also, the correlation coefficient between the CROSS of irrigation water and the amount of Ks was $0.87(p<0.01)$.

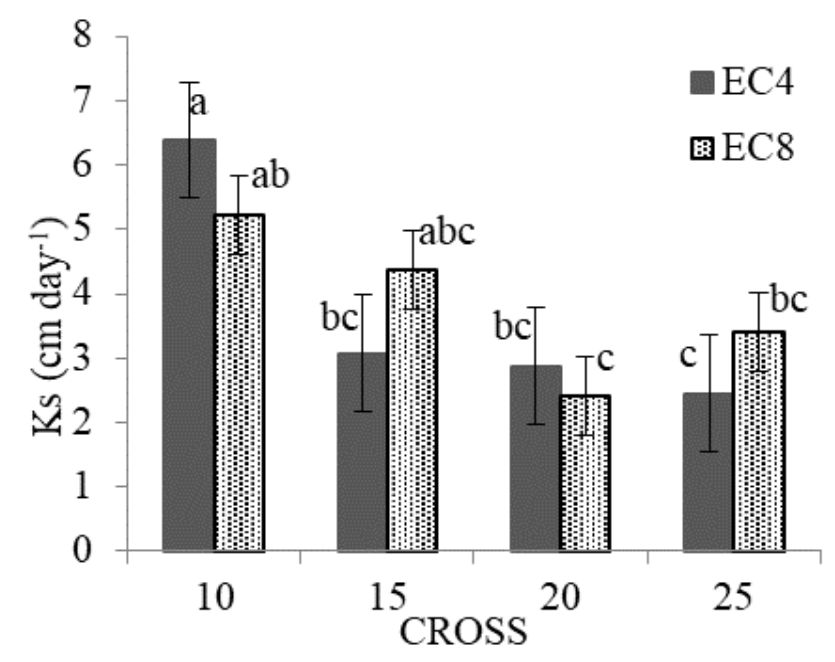

Figure 2: Interaction effect of salinity and CROSS of irrigation water on saturated hydraulic conductivity (similar letters indicate no significant differences among all bars at $p<$ 0.05).

The interaction effect of salinity and CROSS in irrigation water on Ks (Figure 2) showed that for both EC rates, the $\mathrm{Ks}$ value decreased by increasing the CROSS except for $\mathrm{EC}=8 \mathrm{dS} \mathrm{m}{ }^{-1}$ and $\mathrm{CROSS}=25$. For $\mathrm{EC}=4 \mathrm{dS} \mathrm{m} \mathrm{m}^{-1}$, the difference between $\mathrm{CROSS}=10$ and other values was significant, but there was no significant difference between $\mathrm{CROSS}=15,20$ and 25. For $\mathrm{EC}=8 \mathrm{dS} \mathrm{m} \mathrm{m}^{-1}$, despite the decreasing trend of Ks with increasing CROSS values, none of those Ks values were significant from each other. These results revealed that the values of Ks are function of salinity and CROSS and destructive effect of potassium is found at low salinity rates.

\section{The effect of salinity and CROSS of irrigation water on S index}

The slope of retention curve at the inflection point ( $\mathrm{S}$ index) at $\mathrm{EC}=4 \mathrm{dS} \mathrm{m} \mathrm{m}^{-1}$ was significantly $(p<0.05)$ more than that of $8 \mathrm{dS} \mathrm{m}^{-1}$ (Table 4). Dexter (2004) stated that if $\mathrm{S}$ index is larger than 0.035 , soil structure will be good, therefore $\mathrm{S}$ index in salinity of $4 \mathrm{dS} \mathrm{m}^{-1}$ is in good condition, 
while in salinity $8 \mathrm{dS} \mathrm{m}^{-1}$ is less than 0.035 and has a poor structure. It seems that in salinity of $8 \mathrm{dS} \mathrm{m}^{-1}$, this condition is created due to high concentration of potassium cations and in this salinity level, $\mathrm{Ca}^{2+}$ and $\mathrm{Mg}^{2+}$ couldn't prevent the destructive effect of potassium on soil structure. Also, CROSS values had a significant effect on $\mathrm{S}$ index. The more CROSS value, the less $\mathrm{S}$ index that reflects the destructive effects of potassium on soil structure, meanwhile, this trend was achieved up to CROSS $=20$.

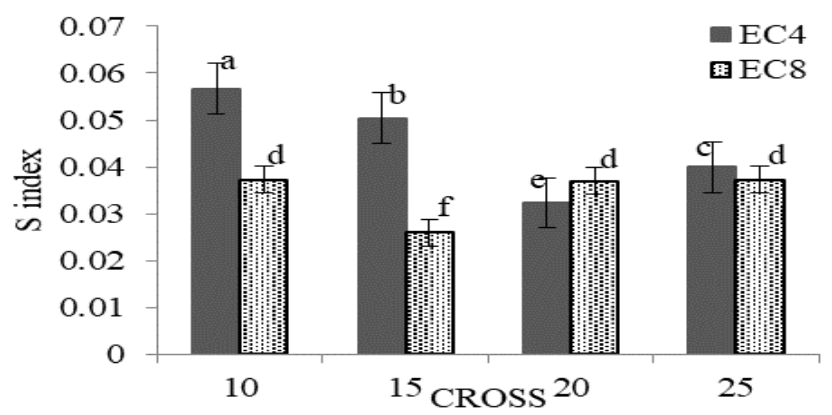

Figure 3: Interaction effect of salinity and CROSS of irrigation water on $S$ index (similar letters indicate no significant differences among all bars at $p<0.05$ ).

The interaction effect of salinity and CROSS value showed that in both salinity levels by increasing the CROSS values up to CROSS $=20, S$ index $(p<0.05)$ decreased (Figure 3 ). The difference between the higher values of CROSS (20 and 25) in salinity of $8 \mathrm{dS} \mathrm{m}^{-1}$ was not significant, while in salinity of $4 \mathrm{dS} \mathrm{m} \mathrm{m}^{-1}$ there was a significant difference between all CROSS values. Indeed, the values of $S$ index in salinity of $4 \mathrm{dS} \mathrm{m}^{-1}$ were more than that of $8 \mathrm{dS} \mathrm{m}^{-1}$. It seems that in high saline irrigation water, with increasing CROSS values, $\mathrm{S}$ index decreased due to destructive effect of potassium and degradation of the soil structure, the negative relationship between $\mathrm{S}$ index and CROSS values was reported by Emami et al. (2014) in saline-sodic soils.

\section{The effect of salinity and CROSS of irrigation water on moisture contents}

The effects of salinity, CROSS and their interaction of irrigation water on moisture contents at FC, PWP, PAWC and the slope of soil moisture curve at inflection point are shown in Table 4 and Figure 4. The results showed that except for FC, other moisture contents changed significantly due to the salinity of irrigation water $(p<0.05)$; such that the highest moisture contents at FC and PWP were obtained in salinity of $8 \mathrm{dS} \mathrm{m}^{-1}$ and the maximum amount of PAWC was achieved in salinity of $4 \mathrm{dS} \mathrm{m}^{-1}$ (Table 4). However, despite the differences among the PWP and PAWC for two salinity values being significant, the increment amounts were negligible. It seems that salinity due to $\mathrm{K}^{+}, \mathrm{Ca}^{2+}$, and $\mathrm{Mg}^{2+}$ has no considerable effect on frequency of macro and micro porosity and thereby on moisture at FC, PWP and PAWC.

The maximum content of FC was found at CROSS $=15$ and it had no significant difference with CROSS $=20$ (Table 4). Other CROSS values were not significantly different. Also, the moisture content at FC was not changed due to the interaction of salinity and CROSS of irrigation water (Figure 4); so that by increasing the CROSS values in both salinity levels ( 4 and $8 \mathrm{dS} \mathrm{m}^{-1}$ ), FC was not changed significantly $(p<0.05)$. These results demonstrated that $\mathrm{Ca}^{2+}$ and $\mathrm{Mg}^{2+}$ prevent the destructive effect of $\mathrm{K}^{+}$in irrigation water and soil solution on the frequency of macro pores and thus moisture content at FC of soil has not changed considerably.

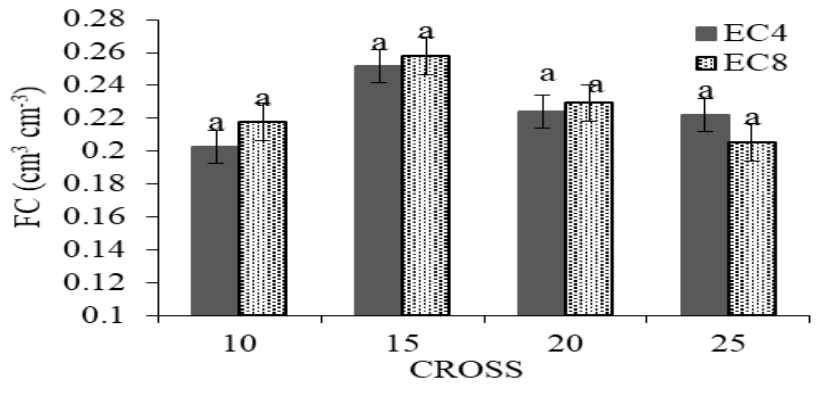

Figure 4: Interaction effect of salinity and CROSS of irrigation water on moisture content of field capacity (similar letters indicate no significant differences among all bars at $p<0.05$ ).

Moisture content at PWP significantly increased by increasing the CROSS value of irrigation water (Table 4). However, there was no difference between CROSS values 20 and 25 . It seems that due to $\mathrm{K}$ cations and increasing the clay dispersion the frequency of micro pores has been increased, therefore the retention of moisture in PWP has been increased. Indeed, it may be said that the moisture content in high suction increased up to the threshold concentration of $\mathrm{K}^{+}$or CROSS value, after that, it probably can't increase the moisture retention. More ever, the interaction effect of salinity and CROSS of irrigation water revealed that at both salinity levels, when CROSS values increased from 10 to 25 the moisture contents of PWP increased too, and in most cases their difference were significant. In salinity of $4 \mathrm{dS} \mathrm{m} \mathrm{m}^{-1}$, the highest amount of PWP was obtained at the highest level of CROSS (Figure 5 ), but the clear trend was not found for salinity of $8 \mathrm{dS} \mathrm{m}^{-1}$. It seems that in somewhat dilute solution an increase in micro pores and thus soil moisture retention at high suctions (15 bar) due to the potassium was obvious; so that $\mathrm{Ca}^{2+}$ and $\mathrm{Mg}^{2+}$ couldn't prevent to compensate the destructive effect of $\mathrm{K}^{+}$on soil structure, therefore, due to clay dispersion 
frequency of micro pores has increased, as a result of this, Ks has decreased (Figure 2), and water retention at PWP has increased.

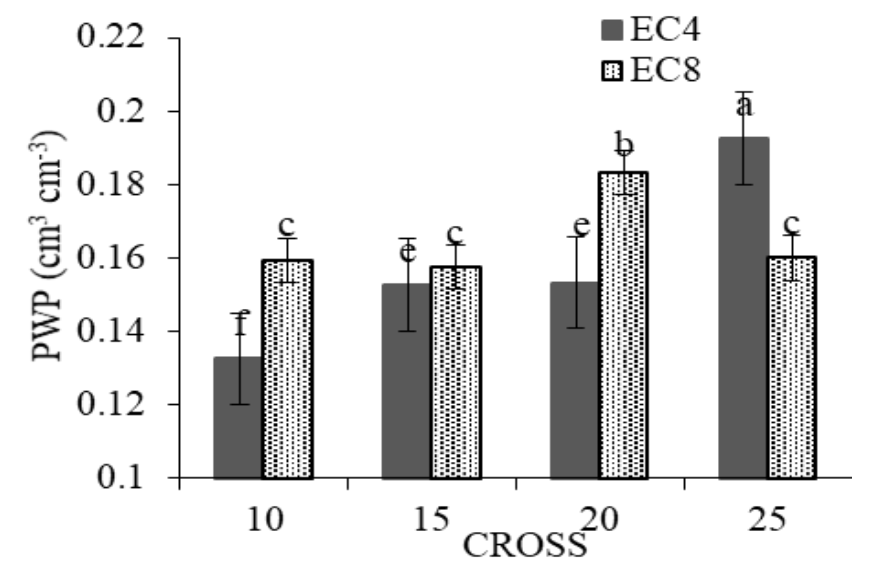

Figure 5. Interaction effect of salinity and CROSS of irrigation water on moisture content of permanent wilting point similar letters indicate no significant differences among all bars at $p<$ 0.05).

The PAWC as well as FC was decreased, when the CROSS value in irrigation water increased from 15 to 25 , and the highest amount of PAWC was found for CROSS 15 (Table 4), while it had the significant difference with the other CROSS values $(p<0.05)$. However, for CROSS 10 it was as similar as 20. The changes of PAWC relate to variation of moisture contents at FC and PWP. Although the moisture content of FC decreased when the CROSS values of irrigation water increased from 15 to 25 , but the reason for increasing the moisture content at $\mathrm{FC}$ due to $\mathrm{K}^{+}$were not clear.

Despite the interaction of salinity and CROSS of irrigation water on PAWC was significant, and all treatments had the significant differences $(p<0.05)$ in salinity level of $4 \mathrm{dS} \mathrm{m}{ }^{-1}$, however trend of PAWC for salinity level of $4 \mathrm{dS} \mathrm{m}^{-1}$ was different from that of $8 \mathrm{dS} \mathrm{m}^{-1}$ (Figure 6). The highest PAWC content for both salinity levels of 4 and $8 \mathrm{dS} \mathrm{m}^{-1}$ was obtained for CROSS 15, while the lowest contents of PAWC were found for CROSS $=25$, and 20 at both salinity level. The PAWC is obtained by subtracting moisture contents at FC from PWP, therefore the reason for irregular trend of PAWC at different levels of salinity and CROSS is due to the different impact of $\mathrm{K}^{+}$ values on frequency of macro and micro pores and thereby the moisture retention in FC and PWP. When the CROSS values increased, the moisture content of $\mathrm{FC}$ for both salinity levels had no significant difference and clear trend, while when the CROSS values increased, the moisture content at PWP slightly increased; so that for salinity of 8 $\mathrm{dS} \mathrm{m} \mathrm{m}^{-1}$ it was more than that of $4 \mathrm{dS} \mathrm{m}^{-1}$. Therefore, the plant available water contents in most CROSS values in EC $=4 \mathrm{dS} \mathrm{m} \mathrm{m}^{-1}$ were more than of $8 \mathrm{dS} \mathrm{m}^{-1}$. The effect of potassium cation or CROSS on soil moisture properties has little been investigated, for example Ruiz et al. (2005) found that when the SAR increased, and soil particles expanded, as a result of expansion, macro porosity decreased, and total porosity increased, thus such soils in a given metric potential will hold higher moisture content than nonexpandable soils or soils without sodium. Also, Hardy (2004) reported that high $\mathrm{Na}^{+}$in the soil leads to a reduction in PAWC, and in our research it seems that a similar condition due to $\mathrm{K}^{+}$has been created.

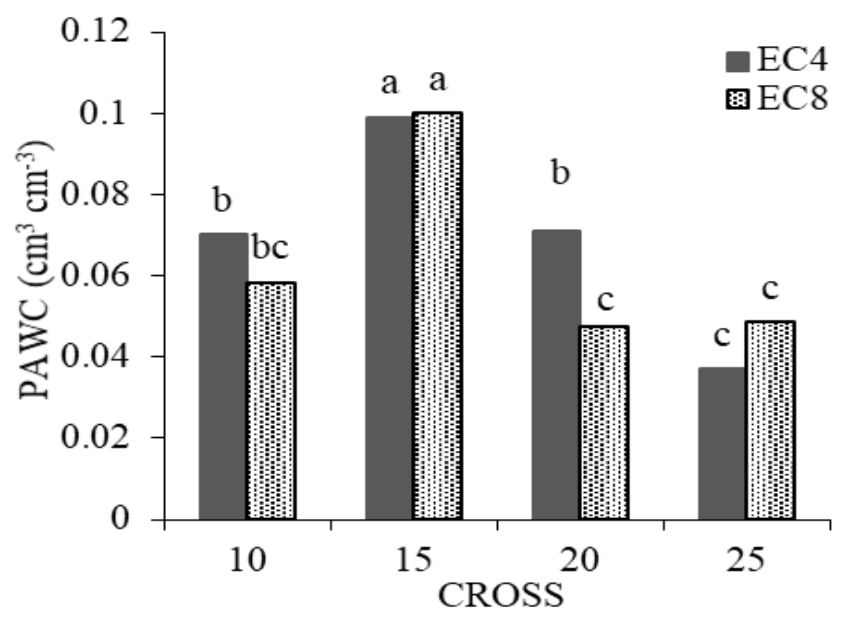

Figure 6. Interaction effect of salinity and CROSS of irrigation water on plant available water content (similar letters indicate no significant differences among all bars at $p<0.05$ ).

\section{Conclusion}

The effect of salinity and CROSS on soil physical properties indicated that the effect of potassium on soil physical properties somewhat depends on the total concentration of solutes and potassium may degrade the soil physical properties like water DC, and S index, as a result of this, the moisture at PWP, and PAWC might decrease. Therefore, considering the destructive effects of sodium and potassium can provide a comprehensive assessment of the structural stability of soils affected by salts in irrigation water. In addition, because we only studied the sandy loam soil, it's recommended that the effect of potassium to bivalent cations ratio on soil physical properties be investigated in other soil textures. 


\section{Competing interests}

The authors declare that they have no conflict of interest.

\section{Acknowledgements}

Appreciation is expressed to Ferdowsi University of Mashhad for financial support of this research.

\section{References}

Ahmad, S., L.D. Swindale and S.A. El-swaify. 2006. Effects of adsorbed cations on physical properties of tropical red earths and tropical black earths. Journal of Soil Science 20(2): 255-268.

Ashraf, M., S.M. Shahzad, M. Imtiaz, M.S.H. Rizwan and M.M. Iqbal. 2017. Ameliorative effects of potassium nutrition on yield and fiber quality characteristics of cotton (Gossypium hirsutum L.) under $\mathrm{NaCl}$ stress. Soil and Environment 36(1): 51-58.

Arienzo, M., E.W. Christen, W. Quayle and A. Kumar. 2009. A review of the fate of potassium in the soil-plant system after land application of wastewaters. Journal of Hazardous Materials 164: 415-422.

Auerswald, K., M. Kainz, S. Angermuller and H. Steindl. 1996. Influence of exchangeable potassium on soil erodibility. Soil Use and Management 12: 117-121.

Bagarello, V., M. Iovino, E. Palazzolo, M. Panno and W.D. Reynolds. 2006. Field and laboratory approaches for determining sodicity effects on saturated soil hydraulic conductivity. Geoderma 130: 1-13.

Chen, Y., A. Banin and A. Borochovitch. 1993. Effect of potassium on soil structure in relation to hydraulic conductivity. Geoderma 30: 135-147.

Dexter, A.R. 2004. Soil physical quality. Part I. Theory, effect of soil texture, density and organic matter, and effect on root growth. Geoderma 120: 201-214.

Dontsova, K.M. and L.D. Norton. 2002. Clay dispersion, infiltration, and erosion as influenced by exchangeable $\mathrm{Ca}$ and Mg. Soil Science 167 (3): 84-193.

Emami, H., A.R. Astaraei, A. Fotovat and M. Khotabaei. 2014. Effect of soil conditions on cation ratio on soil structural stability, structural stability indicators in a sodic soil, and on dry weight of maize. Arid Land Research and Management 28: 325-339.

Emerson, W.W. and B.H. Smith. 1970. Magnesium, organic matter and soil structure. Nature 228: 453-454.

Farahani, F., H. Emami, A. Fotovat and R. Khorassani. 2019. Effect of different $\mathrm{K}: \mathrm{Na}$ ratios in soil on dispersive charge, cation exchange and zeta potential. European Journal of Soil Science 70(2): 311-320.

Farahani, F., H. Emami, T. Keller, A. Fotovat and R. Khorassani. 2018a. Impact of monovalent cations on soil structure. Part I. Results of an Iranian soil. International Agrophysics 32(1). 57-67.

Farahani, F., H. Emami and T. Keller. 2018b. Impact of monovalent cations on soil structure. Part II. Results of two Swiss soils. International Agrophysics. 32(1): 6980.

Hardy, S.M. 2004. Soil sodicity and plant available water capacity maps used to plan sugarcane expansion and potential irrigation requirements in central Queensland. 13th International Soil Conservation Organization Conference. 4-8 July, Brisbane, Australia.

Keren, R. 1991. Specific effect of magnesium on soil erosion and water infiltration. Soil Science Society of America Journal 55: 783-787.

Keren, R. and M. J. Singer. 1988. Effect of low electrolyte concentration on hydraulic conductivity of $\mathrm{Na} / \mathrm{Ca}$ montmorillonite-sand system. Soil Science Society of America Journal 52: 368-373.

Klute, A. and C. Direksen. 1986. Hydraulic conductivity and diffusivity: laboratory methods. p.687-733. In: Methods of Soil Analysis. Part I. Physical and Mineralogical Methods. 2nd Ed. A. Klute (ed.). America Society of Agronomy. Soil Science Society. America, Madison, WI.

Kosmas, C. and N. Moustakas. 1990. Hydraulic conductivity and leaching of an organic saline-sodic soil. Geoderma 46: 363-370.

Laurenson, S. 2010. The influence of recycled water irrigation on cation dynamics in relation to the structural stability of vineyard soils. Ph.D. thesis, Centre for Environmental Risk Assessment and Remediation, University of South Australia, Australia.

Levy, G.J. and J.R. Torrento. 1995. Clay dispersion and macroaggregate stability as affected by exchangeable potassium and sodium. Soil Science 160: 352-358.

Lewis, J. and J. Sjöstrom. 2010. Optimizing the experimental design of soil columns in saturated and unsaturated transport experiments. Journal of Contaminant Hydrology 115-113.

Mandal, U.K., A.K. Bhardwaj, D.N. Warrington, D. Goldstein, A.B. Tal and G.J. Levy. 2008. Changes in soil hydraulic conductivity, runoff, and soil loss due to irrigation with different types of saline-sodic water. Geoderma 144:509-516.

Marchuk, A. 2013. Effect of cations on structural stability of salt-affected soils. Ph.D. Thesis. The University of Adelaide. Australia.

Marchuk, A. and P. Rengasamy. 2012. Threshold electrolyte concentration and dispersive potential in relation to CROSS in dispersive soils. Soil Research 50: 473-481.

McNeal, B.L. and N.T. Coleman. 1966. Effect of solution composition on soil hydraulic conductivity. Soil Science Society of America Journal 20: 389-32. 
Moghbel F., B. Mostafazadeh-Fard, S.A.M. Mirmohammady Maibody and E. Landi. 2017. Salinity management for irrigation with saline-sodic wastewater under corn cultivation. Soil and Environment 36(2): 120-130.

Moosavi, A.A. and A.R. Sepaskhah. 2012. Determination of unsaturated soil hydraulic properties at different applied tensions and water qualities. Archives of Agronomy and Soil Science 58: 11-38.

Quirk, J.P. 2001. The significance of the threshold and turbidity concentrations in relation to sodicity and microstructure. Australian Journal of Soil Research 39: 1185-1217.

Quirk, J.P. and R.K. Schofield. 1955. The effect of electrolyte concentration on soil permeability. Soil Science 6: 163-178.

Rengasamy, P. 2002. Clay dispersion. p.200-210. In: Soil Physical Measurement and Interpretation for Land Evaluation. N. McKenzie, K. Coughlan and $\mathrm{H}$. Cresswell (eds). CSIRO Publishing, Melbourne, Australia.
Rengasamy, P. 2006. World salinization with emphasis on Australia. Journal of Experimental Botany 57: 10171023.

Rengasamy, P. and A. Marchuk. 2011. Cation ratio of soil structural stability (CROSS). Soil Research 49: 280-285.

Ruiz, V., L. Wu and J. Lu. 2005. Effect of sodicity on the water characteristics of six California soils. In The ASA-CSSA- Soil Science Society of America Journal International Annual Meetings. 6-10 Nov. Salt Lake City, UT, USA.

Shainberg, I., J.D. Rhoades, and R.J. Prather. 1981. Effect of low electrolyte concentration on clay dispersion and hydraulic conductivity of a sodic soil. Soil Science Society of America Journal 45: 273-277.

Smiles, D.E. 2006. Sodium and potassium in soils of the Murray-Darling Basin. Australian Journal of Soil Research 44: 727-730.

Van Genuchten, M.Th. 1980. A closed form equation for predicting the hydraulic conductivity of unsaturated soils. Soil Science Society of America Journal 44: 892898. 